Jurnal Sulolipu : Media Komunikasi Sivitas Akademika dan Masyarakat

Vol. 21 No. 12021

e-issn : 2622-6960, p-issn : 0854-624X

\title{
FAKTOR YANG BERHUBUNGAN DENGAN KEJADIAN KECACINGAN PADA ANAK PRASEKOLAH DI KELURAHAN MANGASA KOTA MAKASSAR
}

Factor Factors Related To Genesis Helminthiasis In Preschool Children In The Village Mangasa Makassar

Elsa Novalia Jamal ${ }^{1}$, Abdur Rivai ${ }^{2}$

${ }^{1,2}$ Jurusan Kesehatan Lingkungan

*) elsanovalia201@gmail.com,081224491060

\section{ABSTRACT}

Based on data in 2018 regarding helminthiasis sufferers in pre-school children in kelurahamangasa, tamalate sub-district, Makassar city as many as 123 cases of worms. This study aims to determine what factors are associated with the incidence of helminthiasis in pre-school children in the Mangasa Village, Tamalate District, Makassar City. In this case the cleanliness of nails, washing hands, the habit of wearing footwear. This type of research is observational research with a descriptive approach. The total population in this study were 123 children with random sampling method. Based on the results of the study, the percentage of clean nails of pre-school children in Mangasa Village was $28.72 \%$, the percentage of pre-school children who washed their hands in Mangasa Village was 13.82, and the percentage of pre-school children who wore footwear in Mangasa Village was $93.61 \%$. The results of the research that have been carried out can be concluded that nail hygiene and hand washing have a relationship with the incidence of helminthiasis in pre-school children in the mangasa village, while the habit of wearing footwear is not associated with the incidence of worms in pre-school children in the mangasa village, Makassar city. So it is hoped that the local health center still needs to do health education, especially about worms.

Keywords: worms, pre-school children

\section{ABSTRAK}

Berdasarkan data pada tahun 2018 mengenai penderita kecacingan pada anak pra sekolah di kelurahamangasa, kecamatan tamalate, kota Makassar sebanyak 123 kasus kecacingan. Penelitian ini bertujuan untuk mengetahui faktor-faktor apa saja yang berhubungan dengan kejadian kecacingan pada anak pra sekolah di kelurahan mangasa, kecamatan tamalate, kota Makassar. Dalam hal ini kebersihan kuku, mencuci tangan,kebiasaan memakai alas kaki. Jenis penelitian ini adalah penelitian observasional dengan cara pendekatan deskriptif. Jumlah populasi dalam penelitian ini sebanyak 123 anak dengan metode random sampling. Berdasarkan hasil penelitian diperoleh persentase kuku anak pra sekolah yang bersih di kelurahan mangasa sebanyak $28.72 \%$, persentase anak pra sekolah yang mencuci tangan di kelurahan mangasa sebanyak 13.82, dan persentase anak pra sekolah yang memakai alas kaki di kelurahan mangasa sebanyak $93.61 \%$. Hasil penelitian yang telah dilakukan dapat disimpulkan bahwa kebersihan kuku dan mencuci tangan memiliki hubungan dengan kejadian kecacingan pada anak pra sekolah di kelurahan mangasa sedangkan kebiasaan memakai alas kaki tidak berhubungan dengan kejadian kecacingan pada anak pra sekolah di kelurahan mangasa kota Makassar. Jadi diharapkan kepada pihak puskesmas setempat masih perlunya dilakukan penyuluhan kesehatan khususnya tentang kecacingan.

Kata kunci :kecacingan, anak pra sekolah

\section{PENDAHULUAN}

Infeksi cacing pada manusia banyak dipengaruhi faktor perilaku, lingkungan tempat tinggal dan manipulasi terhadap lingkungan. Penyakit kecacingan banyak ditemukan di daerah kelembaban tinggi dan terutama mengenai kelompok masyarakat dengan personal hygiene dan sanitasi lingkungan yang kurang baik. Kerugian dan dampak akibat infeksi kecacingan tidak menyebabkan manusia mati mendadak tetapi dapat mempengaruhi pencernaan, penyerapan dan metabolisme makanan.

Menurut WHO, 2011 Penyakit kecacingan yang ditularkan melalui tanah atau Soil Transmitted Helminths yang sering dijumpai pada anak pra sekolah yaitu Ascaris Lumbricoides, Trichuris Trichura dan Hookworm. Kecacingan ditemukan hampir terjadi di semua belahan dunia, terutama di Negara-negara yang beriklim tropis. Menurut
Bank Data Global WHO tahun 2006 bahwa kejadian penyakit kecacingan di dunia masih tinggi yaitu 1 milyar orang terinfeksi cacing Ascaris Lumbricoides, 795 juta orang yang terinfeksi cacing Trichuris triciura dan $7 \backslash 40$ juta orang terinfeksi cacing Hookworm. Infeksi kecacingan tertinggi terjadi di Afrika, Amerika, China dan Asia Timur dengan prevelensi kecacingan tertinggi pada anak usia sekolah dasar yaitu 75\% (Sukfitrianty Syahrir,2016).

Anak pra sekolah adalah mereka yang berusia antara tiga sampai enam tahun (Patmonodewo, 1995). Pra sekolah adalah masa anak-anak yang senang berimajinasi dan percaya bahwa mereka memiliki kekuatan. Taman Kanak-kanak adalah salah satu bentuk pendidikan pra sekolah yang menyediakan program pendidikan dini bagi anak usia empat tahun sampai memasuki pendidikan dasar (Supartini, 2004). Salah satu ciri khas perkembangan psikologis pada usia ini adalah mulai meluasnya lingkungan sosial anak. Bila 
Jurnal Sulolipu : Media Komunikasi Sivitas Akademika dan Masyarakat

Vol. 21 No. 12021

e-issn : 2622-6960, p-issn : 0854-624X

pada tahap usia sebelumnya anak merasa cukup dengan lingkungan pergaulan dan keluarga, maka anak usia prasekolah mulai merasakan adanya kebutuhan untuk memiliki teman bermain, serta memiliki aktivitas yang teratur di luar lingkungan rumah. Salah satu permasalahan yang ada adalah tidak semua anak dapat melewati proses perkembangannya dengan baik.

Sulawesi selatan adalah salah satu provinsi di Indonesia yang cukup menjadi perhatian selain karena potensi yang dimiliki dalam bidang ekonomi, perdagangan dan pariwisata.Berdasarkan data dari Dinas Kesehatan Provinsi Sulawesi Selatan bahwa penderita kecacingan di Sulawesi Selatan masih terpaling banyak yaitu pada tahun 2015 (14.288 kasus), 2016 (9.639 kasus), 2017 (10.488 kasus), 2018 (7.237 kasus). Selanjutnya berdasarkan data dari Dinas Kesehatan Kabupaten/kota bahwa Makassar menjadi kota tertinggi penderita kasus kecacingan. Jumlah penderita kecacingan di kota Makassar berdasarkan laporan Dinas Kesehatan Kabupaten/kota mengalami peningkatan dari tahun 2013 (3.226 kasus), 2014 (3.266 kasus), 2015 (3.270 kasus). (Andi Tri Reski Amalia,2016).

Adapun salah satu daerah tertinggi kasus kecacingan di kita Makassar tepatnya berada di daerah Mangasa, Gunung Sari dan Manuruki kota Makassar. Iklim tropis di daerah ini mendukung siklus perkembangbiakan cacing khususnya Ascaris Lumbricoides, selain itu juga didukung oleh kondisi hygiene perseorangan penduduk disana yang kurang baik. Berdasarkan data yang diperoleh dari Puskesmas Mangasa di wilayah tersebut pada tahun 2018 anak pra sekolah (123 kasus) dan anak usia sekolah (1385 kasus). (Data puskesmas Mangasa, Tamalate Kota Makassar).

observasional dengan pendekatan deskriptif. Penelitian ini dilakukan pada Kelurahan Mangasa, Tamalate kota Makassar. Populasi dalam penelitian ini adalah Anak Pra sekolah penderita kecacingan di kelurahan Mangasa, Tamalate kota Makassar dengan jumlah 123 anak. Sampel dalam penelitian ini adalah anak pra sekolah dengan jumlah 94 sampel dengan Cara pengambilan sampel menggunakan simple random sampling.

\section{PENGOLAHAN DATA}

Tehnik pengolahan data dianalisa secara deskriptif dalam bentuk tabel disertai dengan analisa informasi antara variabel serta uraian yang didasari pada dasar teori pendukung

\section{HASIL PENELITIAN}

Berdasarkan hasil penelitian yang dilakukan pada bulan maret-april 2019 tentang faktor-faktor yang berhubungan dengan kejadian kecacingan pada anak pra sekolah di Kelurahan Mangasa Kota Makassar sebagai berikut:

Tabel 1

Data kecacingan anak pra sekolah di puskesmas Mangasa kota makassar berdasarkan umur tahun 2019

\begin{tabular}{cccc}
\hline No. & Umur & Jumlah & $\%$ \\
\hline 1 & 3 & 10 & 10,63 \\
\hline 2 & 4 & 32 & 34,04 \\
3 & 5 & 25 & 26,59 \\
\hline 4 & 6 & 27 & 42,18 \\
\hline Total & & 94 & $\mathbf{1 0 0}$ \\
\hline
\end{tabular}

\section{METODE}

\section{Desain, tempat dan waktu}

Variabel bebas adalah variabel yang mempengaruhi variabel terikat yang terdiri dari kebiasaan memotong kuku, kebiasaan mencuci tangan, dan kebiasaan memakai alas kaki. Variabel terikat adalah variabel yang di pengaruhi oleh variabel bebas dalam hal ini penderita kecacinga Jenis penelitian yang digunakan pada penelitian ini adalah penelitian

Tabel 2

Distribusi tingkat kebersihan kuku anak pra sekolah penderita kecacingan di Kelurahan Mangasa Kota Makassar Tahun 2019

\begin{tabular}{cccc}
\hline No. & $\begin{array}{c}\text { Kebersihan } \\
\text { Kuku }\end{array}$ & Jumlah & $\%$ \\
\hline 1 & Ya & 27 & 28,72 \\
2 & Tidak & 67 & 71,28 \\
\hline Total & & $\mathbf{9 4}$ & $\mathbf{1 0 0}$ \\
\hline
\end{tabular}


Jurnal Sulolipu : Media Komunikasi Sivitas Akademika dan Masyarakat

Vol. 21 No. 12021

e-issn : 2622-6960, p-issn : 0854-624X

Tabel 3

Distribusi tingkat cuci tangan anak pra sekolah penderita kecacingan di Kelurahan Mangasa Kota Makassar 2019

\begin{tabular}{cccc}
\hline No. & $\begin{array}{c}\text { Cuci } \\
\text { Tangan }\end{array}$ & Jumlah & $\%$ \\
\hline 1 & Ya & 13 & 13,82 \\
2 & Tidak & 81 & 86,18 \\
\hline Total & & $\mathbf{9 4}$ & $\mathbf{1 0 0}$ \\
\hline
\end{tabular}

Tabel 4

Distribusi tingkat kebiasaan memakai alas

kaki anak pra sekolah penderita

kecacingan di Kelurahan Mangasa Kota

Makassar

Tahun 2019

\begin{tabular}{cccc}
\hline No. & $\begin{array}{c}\text { Memakai } \\
\text { Alas Kaki }\end{array}$ & Jumlah & $\%$ \\
\hline 1 & Ya & 88 & 93,61 \\
2 & Tidak & 6 & 6,39 \\
\hline Total & & $\mathbf{9 4}$ & $\mathbf{1 0 0}$ \\
\hline
\end{tabular}

\section{PEMBAHASAN}

Hubungan kebersihan kuku dengan kejadian kecacingan pada anak pra sekolah di kelurahan mangasa kota Makassar. Kebersihan kuku merupakan faktor yang diduga turut berpengaruh dengan kejadian kecacingan. Kecacingan adalah penyakit yang terjadi karena terinveksinya kuman penyakit kepada manusia yang disebabkan kurangnya kepedulian terhadap kesehatan dan kebersihan diri. Menurut Luize (2004) penularan cacing diantaranya melalui tangan yang kotor. Kuku jari tangan yang kotor kemungkinan akan tertelan ketika makan jika tangan tidak dicuci dengan baik. Sedangkan sesorang dikatakan kukunya bersih jika dipotong setiap seminggu sekali.

Berdasarkan dari hasil penelitian ini didapatkan hasil bahwa responden yang menjaga kebersihan kuku sebanyak $28,72 \%$ dan yang tidak menjaga kebersihan kuku sebanyak $71,28 \%$. Hal ini sejalan dengan penelitian yang dilakukan andi Tri Reski Amalia "distribusi spasial kasus kecacingan (Ascaris Lumbricoides) terhadap personal higiene anak balita di pulau Kodingareng Kecamatan Ujung Tanah Kota Makassar 2016".

Kuku yang terawat tentu saja akan terlihat bersih dan tidak panjang. Sedangkan kuku yang tidak terawat akan terlihat kotor, hitam penuh kuman dan panjang. Kuku yang panjang tentu saja jarang dipotong atau dipotong pada saat sudah melebihi dari satu minggu bahkan dua minggu. Tapi dalam penelitian ini menyatakan bahwa kuku dari sekian responden tidak terjaga dengan baiksehingga kebersihan kuku ada hubungannya dengan kejadian kecacingan di kelurahan mangasa kota makassar.

Hubungan cuci tangan dengan kejadian kecacingan pada anak pra sekolah di kelurahan mangasa kota makassar. Mencuci tangan adalah salah satu tindakan sanitasi dengan membersihkan tangan dan jari jemari menggunakan air dan sabun oleh manusia untuk menjadi bersih dan memutus mata rantai kuman penyakit. Menurut dr.Leo Indarwahono (2012) mencuci tangan menggunakan sabun dan air mengalir dapat memutus mata rantai kuman yang melekat di jari jemari.

Berdasarkan hasil penelitian ini didapatkan hasil bahwa responden yang mencuci tangan sebanyak $13,82 \%$ dan yang tidak mencuci tangan sebanyak $86,18 \%$. Hal ini sejalan dengan penelitian Skufitrianti Syahrir"Faktor yang berhubungan dengan kejadian kecacingan pada siswa SDN Inpres No.1 Wora Kecamatan Wera Kabupaten Bima 2016". Sehingga kebiasaan mencuci tangan baik sebelum makan, sesudah BAB, sesudah bermain, cuci tangan di air mengalir, cuci tangan pakai sabun, pengeringan tangan dengan handuk dan cuci tangan sebelum jajan memiliki hubungan yang sangat erat dengan kejadian kecacingan pada anak pra sekolah di kelurahan mangasa kota makassar.

Infeksi kecacingan dapat dipengaruhi oleh beberapa faktor salah satunya kabiasaan cuci tangan khususnya sebelum makan akan meningkatkan terjadinya inveksi kecacingan hal ini dapat dilihat dari hasil penelitain yang menyatakan bahwa sampel dengan kebiasaan mencuci tangan yang tidak baik mengalami infeksi lebih banyak dari anak yang memikliki kebiasaan mencuci tanagn dengan baik yaitu dengan mencuci tangan mencuci tangan baik sebelum makan, sesudah BAB, sesudah bermain, cuci tangan di air mengalir, cuci tangan pakai sabun, pengeringan tangan dengan 
Jurnal Sulolipu : Media Komunikasi Sivitas Akademika dan Masyarakat

Vol. 21 No. 12021

e-issn : 2622-6960, p-issn : 0854-624X

handuk dan cuci tangan sebelum jajanmemiliki peran penting untuk mencegah terjadinya penyakit kecacingan.

Kebiasaan mencuci tangan merupakan syarat penting dalam mencegah terjadinya penyakit menular seperti kecacingan. Namun lingkungan dan kebiasaan mencuci tangan yang tidak baik akan mempengaruhi kejadian kecacingan hal ini dikarenakan pada usia pra sekolah belum mampu mandiri untuk mengurus kebersihan diri. Hubungan kebiasaan memakai alas kaki dengan kejadian kecacingan pada anak pra sekolah di kelurahan mangasa kota makassar

Kebersihan diri merupakan langkah awal mewujudkan kesehatan diri. Dengan tubuh yang bersih meminimalkan resiko seseorang terhadap kemungkinan terjangkitanya suatu penyakit, terutama penyakit yang berhubungan dengan kebersihan diri yang buruk. Tanda-tanda seseorang kurang perawatan diri yaitu, penampilan dekil, badan bau, rambut kumal, kuku panjang dan kotor serta tubuh dipenuhi dengan penyakit kulit. Itulah sebabnya dianjurkan untuk kita menjaga kebersihan diri salah satunya bagi anak-anak untuk selalu menggunakan alas kaki karna hal tersebut bisa menyebabakan terjadinya penyakit.

Berdasarkan penelitian yang telah dilakukan didapatkan hasil bahwa responden yang menggunakan alas kaki sebanyak 93,61\% dan yang tidak menggunakan alas kaki sebanyak $6,39 \%$. Hal ini sejalan dengan penelitian yang dilakukan andi Tri Reski Amalia distribusi spasial kasus kecacingan (Ascaris Lumbricoides) terhadap personal higiene anak balita di pulau Kodingareng Kecamatan Ujung Tanah Kota Makassar 2016". Sehingga dinyatakan bahwa kebiasaan memakai alas kaki tidak ada hubungannya dengan kejadian kecacaingan pada anak pra sekolah di kelurahan mangasa kota makassar.

\section{KESIMPULAN}

Berdasarkan hasil penelitian yang telah dilakukan dapat disimpulkan bahwa kebersihan kuku dan cuci tangan memiliki hubungan dengan kejadian kecacingan di kelurahan mangasa, sedangkan memakai alas kaki tidak berhubungan dengan kejadian kecacingan di kelurahan mangasa kota Makassar.

\section{SARAN}

Diharapkan untuk lebih meningkatkan penyuluhan kepada masyarakat tentang pentingnya menjaga kesehatan agar terhindar dari penyaakit, dan untuk peneliti selanjutnya agar meneliti tentang factor apa yang menyebabkan memakai alas kaki tidak memiliki hubungan dengan kejadian kecacingan

\section{UCAPAN TERIMA KASIH}

Terima kasih kepada seluruh pihak yang sudah memberikan bimbingan, bantuan, motivasi dan arahan dalam penyelesaian Penelitian

\section{DAFTAR PUSTAKA}

Agustaria Ginting. 2008. Faktor-Faktor Yang Berhubungan Dengan Kejadian Kecacingan Pada Anak Sekolah Dasar Di Desa Tertinggal Kecamatan Pengururan Kabupaten Samosir Tahun 2008.(online). (repository.usu.ac.id diakses 29 Desember 2018).

Ajen Angelina. 2017. Tumbuh kembang Anak Pra Sekolah Usia tiga samapi enam tahun. Kesehatan Lingkungan. Oktober 2017. HIm 1.(Online). (ajenangelina.com diakses 3 Januari 2019).

Andi Tri Reski, Azriful. 2016. Distribusi Spasial Kasus Kecacingan (Accaris Lumbricoides) terhadap Personal Hygiene Anak Balita di Pulau Kodingareng Kecamatan Ujung Tanah Kota Makassar Tahun 2016. Kesehatan Lingkungan, Volume 2, Nomor 2, hal 75. (Online). (journal.uin- alauddin.ac.id diakses 28 Desember 2018).

Dinas kesehatan provinsi Sulawesi selatan. 2019. Data Dinas kesehatan provinsi Sulawesi selatan. 2018. Makassar: Dinas kesehatan provinsi Sulawesi selatan 
Jurnal Sulolipu : Media Komunikasi Sivitas Akademika dan Masyarakat

Vol. 21 No. 12021

e-issn : 2622-6960, p-issn : 0854-624X

Leo indarwahono. 2012. Cuci Tangan Pakai Sabun Cegah Kuman Penyebab Penyakit. (online).(www.tribunnews.com diakses 3 januari 2019).

Lisdawati. 2011. Kondisi Hygiene Perorangan Terhadap Infeksi Kecacingan Pada Anak-Anak Di Kelurahan Banta-Bantaeng Kota Makassar. Makassar: Poltekkes Makassar Jurusan Kesehatan Lingkungan. (Skripsi Tidak Diterbitkan.)

Patmonodewo. 1995. Buku Ajar Pendidikan Prasekolah. Jakarta: Departemen Pendidikan Dan Kebudayaan

Puskesmas Mangasa. 2019. Data puskesmas Mangasa, Tamalate Kota Makassar 2018. Makassar: Puskesmas Mangasa

Rita Eka izzaty. 2017. Perilaku Anak Pra Sekolah.Yogyakarta:Elex Media Komputindo.

Sasongko. 2009. Penyuluhan Tentang Infeksi Kecacingan Dan Upaya Pencegahannya.Surabaya: EGC Sentosa Sembiring. 1987. Kebiasaan Penggunaan Alas Kaki. Jakarta: Rineka Cipta

Soekidjo Notoatmojo. 2007. Ilmu Perilaku Kesehatan. Jakarta: Rineka Cipta

Sri wahyuni. 2014. Hubungan Perilaku Hidup Bersih Dan Sehat (PHBS) Dengan Kejadian Penyakit Kecacingan Di SDN 1 Kelurahan Karuwisi Kecamatan Panakkukang Kota Makassar. Makassar. Poltekkes Makassar Jurusan Kesehatan Lingkungan.(Skripsi tidak diterbitkan)

Sukfitrianty Syahrir, Aswadi. 2016. Faktor yang Berhubungan dengan Kejadian Kecacingan pada Siswa SDN Inpres No. 1 Wora Kecamatan Wera Kabupaten Bima. Kesehatan Lingkungan. Volume 2, Nomor 1. (Online). (journal.uin-alauddin.ac.id diakses 28 Desember 2018).

Suriani. 2013. Hubungan hygiene perorangan dengan kejadian infeksi kecacingan pada anak sekolah dasar 5 muhammadiyah kelurahan rappocini kecamatan rappocini kota makassar. Makassar: Poltekkes makassar jurusan kesehatan lingkungan. (Skripsi tidak di terbitkan)

Zaidina Umar. 2008. Perilaku Cuci Tangan Sebelum Makan Kecacingan Pada Murid SD di Kabupaten Pesisir Selatan Sumatera Barat. Kesehatan Lingkungan. (Online). (zaidinaumar.com diakses 3 januari 2019) 